$A-B$ [ancroft, w., ]

$\gamma \quad 1922$

$\frac{x}{5}$

$\frac{3}{\frac{3}{3}}$

3
$\frac{1}{3}$
$\frac{3}{3}$

Q

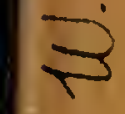

$\alpha$

है

3 


\section{HARVARD UNIVERSITY.}

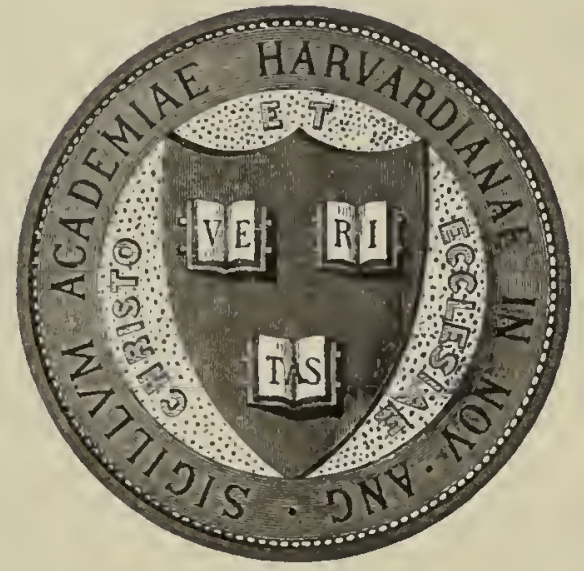

LIBRARY

OF THE

MUSEUM OF COMPARATIVE ZOÖLOGY 62,540

GIFT OF

$$
\text { Outram Bange }
$$

Yovember 17. 1923. 


\title{
Iridescent Colors in Feathers ${ }^{2}$
}

\author{
By Wilder D. Rancroft \\ CORNELL UNIVERSITY, ITHACA, N. Y.
}

$\mathrm{A}^{\mathrm{T}}$

T THE Rochester meeting I reported on the structural blues in feathers. That left the metallic or iridescent colors to be acrounted for. Michelson² believes that the colors in the tail of the peacock and the throat of the humming bird are due to selective reflection, like the yellowish green metallic color of solid magenta. I,ord Rayleigh ${ }^{3}$ maintains that the colors are the interference colors of thin films, often referred to as Newton's rings. Since the question seemed to involve coöperative research by men representing different fields, the Heckscher Research Council made a grant to a committee consisting of Messrs. Bancroft, Chamot, and Merritt, representing physical chemistry, chemical microscopy, and physics. As an unofficial member representing ornithology, the committee has had the enthusiastic coöperation of Mr. Louis Agassiz Fuertes, who was really responsible initially for the starting of the whole investigation. The work of the committee has been facilitated by the courtesy of Prof. A. A. Allen of Cornell University and of Dr. Frank M. Chapman of the Natural History Museum, who have supplied us with many typical feathers. For the experimental work the committee has been fortunate in securing the assistance of $\mathrm{Mr}$. Clyde W. Mason, assistant in chemical microscopy at Cornell University. It is to his skill and perseverance that the successful outcome of the investigation is due.

While the nonmetallic blues are always in the barbs, the iridescent colors are wholly in the barbules, the barbs in such feathers being a dark dull brown and showing no color effects. The iridescent colors are visible by reflected light from both surfaces of the features but cannot be seen by transmitted light. By transmitted light the feathers of the blue jay, the tail feathers of the peacock and the throat feathers of the humming bird show no more signs of brilliant colors than do the feathers of a crow.

There is not only no bright color to be seen by transmitted light in any metallic or iridescent feather, but no bright-colored pigment can be extracted by boiling with any organic liquid. If the dark or melanin pigment is extracted, the metallic color remains with little change until the dark pigment is practically all gone and can be detected even then when the feather is ex-

1 The investigation upon which this article is based was supported by a grant from the Heckscher Foundation for the Advancenent of Research, established by August Heckscher at Cornell University.

2 Phil. Mag., [6] 21 (1911), 554

Ibid., [6] 37 (1919), 98. 
amined under the microscope. The change in color with changing angle of incidence is that corresponding to interference colors, and is much greater than with substances like magenta, showing selective reflection. In fact, the change of color with changing angle of incidence is practically negligible with magenta and the other pigments of this type. The natural conclusion is, therefore, that the iridescent colors are not due to selective reflection.

The color's of iridescent feathers belong to Newton's series of interference colors, being caused by a laminated or plate-like structure of the barbules, where the color originates. These barbules present broad, flat surfaces forming an approximately plane surface which exhibits the colors with great brilliancy. The cross section of the barbule shows a central pith or core about two microns thick, which appears to be of somewhat fibrous or granular character. Enveloping this core are three thin layers or laminae, of equal and uniform thickness, and seemingly in contact. The color originates in these three layers, each about $0.4 \mu$ thick, which make the barbule act as a multiple thin film. The laminated outer layer of the barbules is particularly characteristic, and was not found on the nonmetallic feathers of the same bird where these were available for examination. In all cases a definite structure is associated with metallic luster. The barbules are always broad and flattened, distinctly segmented, with blunt ends, and generally contain much more dark pigment than adjacent noniridescent barbules of the same feather. Altum" says that "the metallic luster is always associated with the peculiar, hard, and smooth texture. A blind man could easily pick out all the birds with metallic luster in a collection of any size." The relation between structure and metallic luster is so close that Mr. Mason was able to pick out from the collection of drawings of barbules in Chandler's paper ${ }^{5}$ those which were of the metallic type. Comparison with the description of the coloring of the feather showed very few errors, even though the drawings cover almost all species and include many feathers not possessing any noniridescent barbules for comparison.

The thickness of these films is about the value calculated for the interference colors of the order observed in feathers, though the whole structure is too small for very accurate measurements. In all the iridescent feathers examined, the colors appear to lie in the upper second or third orders of the series, which include the most brilliant of the interference colors-yellow, and red in the upper second order, and dull purple, blue, green, yellow, and red in the third order. Since we have no good method of determining exactly the order of interference and isolated color reflected from a thin film, this is based on matching the colors of feathers with those of artificial films, the colors of which are of known order.

With increasing angle of incidence the color usually changes through two or three of the colors of the above series. The change is frequently from the blue to the red end of the spectrum, but this is not necessarily the case. The pigeon, for instance, has

$4 J$. Ornithologie, 2 (1854), 19.

5 University of California Publications, Zoölogy, 13, No. 11 (1914-16). 
feathers which change from bluish grcen through red to yellowish green with increasing angle of incidcnce. Thickcning of the color-producing films by swelling rcsults in a color change toward a color listed in a series after the original color, for the order of the color is higher the thicker the film. Thinning by pressure or in fault bars results in a color of lower order (earlier in the seties) than the original color of the barbules.

Bleaching does not destroy the colors, because there is no bright pigment to be destroycd, but only a structure; and the iridescence is uninjured unless the structure is destroyed. The metallic luster and brilliancy of iridescent feathers is due to the dark brown pigment in them, which serves as a dark background for the interference colors. The exact distribution of this dark pigment is not certain; but apparently no special distribution is necessary to give the metallic luster, provided the essential structure is present, for the white, faintly iridescent, pigeon feathers become brilliant and metallic when dyed with a brown dye, though a detailed study of sections of the dyed barbules shows a rather uniform distribution of the dye instead of segregation in one underlying layer. It is possible that a neutralcolored, transparent, thin film may serve to some extent as its own dark background, producing brilliant colors and a metallic luster, as does a colorless film on a dark background. As a matter of fact, we get brilliant colors with thin films of asphaltum varnish.

The metallic colors can be duplicated very satisfactorily by putting a thin film of a colorless varnish over a dark pigeon's feather, but the result is more garish than the real feather, because the film spreads over the feather as a whole instead of over each individual barbule. The curvature of the barbules, with the resultant complexity of the surface of the feather, results in a softening and blending of the garish colors noticed in plane, thin films, because of the different angles at which different parts of the curved surface are viewed. This causes a mingling of the colors seen at normal and at other angles of incidence, giving added softness and richness of color. The slight local variations in the thickness of the color-producing film also contribute to this effect by causing a mottling of colors, which mingle and appear to the eye as the mean color of all the various hues. The color which we observe on the feather is thus the result of the iningling of a number of colors adjacent in Newton's series, which produce the effect of a single, softer color. No one can deny that the colors of thin oil filns on a pavement are garish.

Variation in the thickness of the color-producing films explains the different colors often observed on a single feather, either in the form of a pattern, as in the case of the peacock, or in gradations of color, such as are scen in the feathers of the starling, purple grackle, Lamprocolius phoenicopterus bispecularis, and other birds. Such iridescent feathers show bands of colors which remind one very much of the colors produced by oil on an asphalt pavement. For instance, some of the feathers of the starling are iridescent reddish purple at the base shading to 
yellowish bronze at the tip; others are yellowish green at the base to greenish blue at the tip; while some feathers of the purple grackle shade from reddish purple at the base to blue, greenish blie, green, yellow-green, to yellow-bronze at the tips. These sequences of shades are undoubtedly produced by a gradual variation in thickness of the color-producing films, for the colors adjacent on the feather are always adjacent in Newton's series, and, moreover, the colors shift with increasing incidence, just as do Newton's rings, the shift or change in position of a given color being toward the thicker part of the film.

The grosser structure of the feather may influence the appearance of the iridescent colors very markedly. Not only the perfection of the surface formed by the overlapping of the distal barbules, but also the visibility of the color, are dependent on this. For example, the blue-green iridescent barbules of the peacock feather are present in the black center of the "eye;" but are arranged so that they are seen edgewise and their color ordinarily does not appear. The iridescent colors of many birds, particularly humming birds, are often visible only from a position in front of the bird, and are quite invisible when the head of the bird is pointed away from the observer. This, again, is due to the barbules which are so arranged that, instead of having their planes in the general plane of the feather, they are skewed or tilted somewhat, and lie normal to a direction toward the head of the bird, rather than in the plane of the feather. Consequently, they are seen edgewise from other positions, and give little or no color.

One marvels at the way in which these colors are produced with such uniformity on different feathers and different birds throngh successive generations, in spite of the fact that a very slight variation in the thickness of the films would alter the color effect greatly. The production of iridescence seems to present a most remarkable case of the regulation of an essential structure within very sharply defined limits, not only in numerous individuals but also through many successive generations. Perhaps more remarkable still is the case of the white peacock. We had hoped that the tail feathers of the white peacock differed from those of the ordinary peacock only in not having the dark pigment present, in which case dyeing the feather or painting the back of it black wonld bring out the brilliant metallic colors. This does not happen because the tail feathers of the white peacock do not have at all the same structure as those of the ordinary peacock. In spite of the absence of color and the complete difference in structure, the general pattern of the peacock feather has been preserved in the white peacock even though the effect is produced in an entirely different way. This must have some great biogenetic significance, though fortunately that is not a problem for the chemist.

When this work was begun, the committee believed strongly in Michelson's theory of selective reflection; but it was soon found that this theory conld not be applied satisfactorily to the phenomena observed, and the conclusion was reached finally that Michelson was wrong and Lord Rayleigh was right. The 
iridescent colors of feathers are caused by thin laminae or films in the barbules which produce interference colors. No colors due to selective reflection have been detected in any of the metallic feathers which have been studied. The birds examined include:

Black Minorcas and Rhode Island Reds (Gallus)

Bronze-winged Pigeon (Columbia phaps)

Common Pigeon

Green Heron (Ardea virescens)

Wood Duck (A ex sponsa)

Mallard (Anas boschas)

Sommering Pheasant (Phasanius sommeringi)

Monaul Pheasant (Lophophorus impeyanus)

Golden Pheasant (Thumalea picta)

Chinese Pheasant (Phasanius torqualus)

Peacock Pheasant (Polyplectrum bicalcaratum)

Bronze-headed Trogon

Peacock (Pavo cristatus)

Musciroia mexicana

Ptilopus puella

Ptilopus pulchellus

Lamprocolius phoenicoplerus bispecularis

Purple Grackle (Quiscalus purpureus)

Jacamar (Jacamarops aureus)

Ruby-throated Humming Bird (Trochilus colubris)

Red Kingbird of Paradise

Wild Turkey (Meleagris americana)

Nettion brasiliense

Starling (Sturnus vulgaris)

Muscovy Duck (Cairina moschata) 





$$
\begin{aligned}
& \text { Photomount } \\
& \text { Pamphlet } \\
& \text { Binder } \\
& \text { Gaylord Bros. } \\
& \text { Makers } \\
& \text { Syracuse, N. Y. } \\
& \text { PAT. JAN 21, 1908 }
\end{aligned}
$$


$x_{1}+2=$

$$
-3 y^{2}
$$

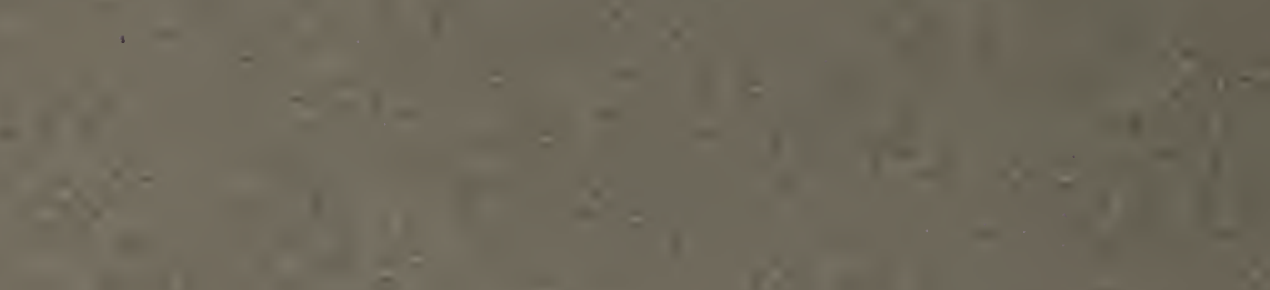

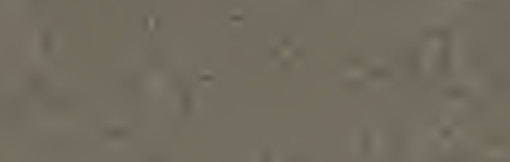

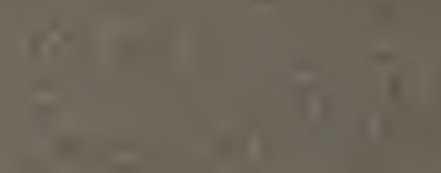

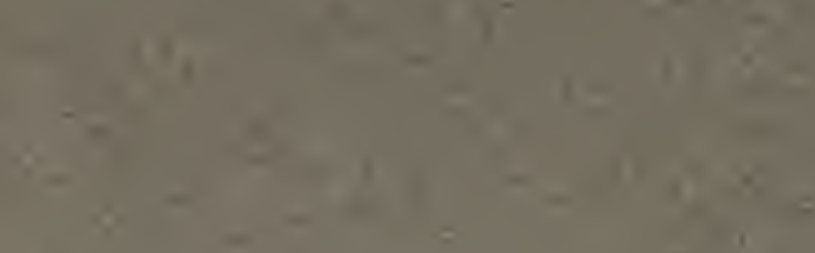

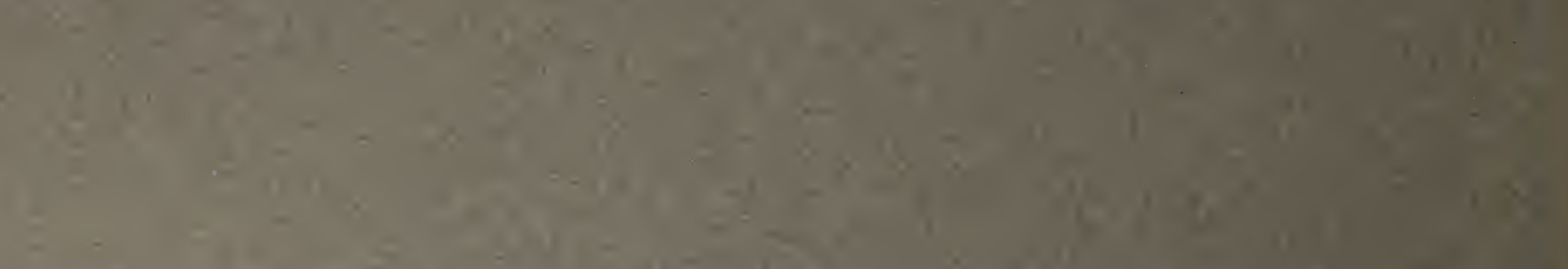

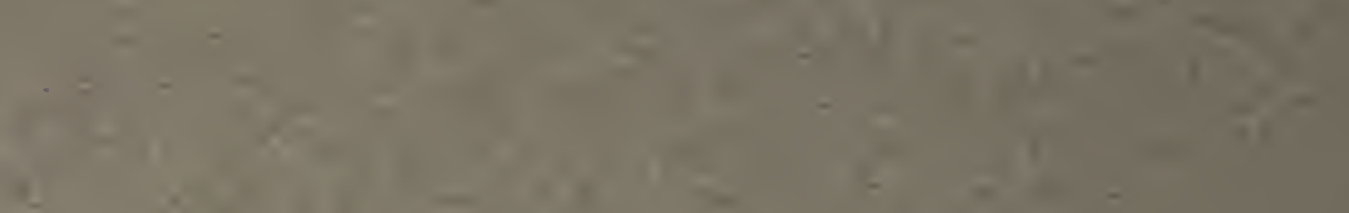

